\title{
THE EFFICASY OF MUSIC IN LOWERING INTRA-OPERATIVE SEDATION REQUIREMENT AND RECALL OF INTRA OPERATIVE PROCESSES
}

\author{
Vijay Sharma \\ (MBBS, DA, $M D, D N B)$, Benhur Premendran (MBBS, $M D$ ), Himaunshu Dongre (MBBS, $M D$ ), \\ Usha Domkondwar (MBBS, DA, MD) \\ Department of Anaesthesiology, Mahatma Gandhi Institute Of Medical Sciences, Sevagram,
}

\begin{abstract}
Background: It has been known for a long time that music has characteristic psychological and physiological effects in humans. It is a non-pharmacological technique that is inexpensive, non invasive and has no major side effects. Surgery with music is being increasingly reported at many of the today's modern hospitals, documenting music's powerful soothing, calming, sedating effects on subjects including a significant reduction in the amount of anesthesia needed. Aims and Objectives: To find out whether patients undergoing elective surgery under regional anesthesia, who hear a preselected music during surgery through a headphone, need a lower dose of intra-operative sedatives and have a reduced recall of intra-operative processes

Methods: 60 Patients undergoing elective orthopedic,gynaecological or urological Surgeries under regional anaesthesia between June to August 2009 were randomized into either listening to Music(group M,n=30), or not listening to music(group $\mathbf{C}, \mathrm{n}=30$ ). Midazolum was given for sedation in either of the groups to achieve a Observer's Assessment of Sedation/Alertness Score(OAS) of 3 or less.We compared the total dose of Midazolum required and OAS scores in both the groups. Post operative recall of Intraoperative processes by patient was assessed on answers to a 6 point Questionnaire and VAS score for pain,discomfort and dissatisfaction with the sedative method employed was sought. Results:The Mean dose Of Midazolum to achieve Sedation was significantly lower $(\mathrm{p}<0.01)$ in the patients that listened to Music during their surgery.Desirable OAS score $(<3)$ were significantly better in the Music group at 90 ant 120 min from start of the surgery. There was no significant differences in the VAS scores for pain ,discomfort or dissatisfcation with the sedation method employed in either groups $(\mathrm{P}>0.01)$. Intra operative instances of conversations between the doctors/nurses and other OR staff and Sounds of monitors, instruments, etc were more significantly recalled by those who did not listened to music during their surgery $(\mathrm{P}<0.01)$.

Conclusion: Our study concludes that patients undergoing elective surgery under regional anesthesia, who hear a preselected music during surgery through a head-phone, need lower dosage of intra-operative sedatives and have a reduced recall of intra-operative processes thus creating an effective,safe and cheap non pharmacological method of sedating conscious patients operated under regional anaesthesia.We recommend that Favourite Music via headphones should be provided to all the patients who are fond of music listening during the surgical procedures expected to last one and half hours or more .
\end{abstract}

Keywords: Music, Intraoperative sedation, Recall of intraoperative processes.

\section{INTRODUCTION:}

The search for improved and cost effective means of enhancing patient's outcome in the immediate post-operative period has lead to evaluation of the effectiveness of non-pharmacological interventions in improving patient recovery (1). It has been known for a long time that music has characteristic psychological and physiological effects in humans. It is a nonpharmacological technique that is inexpensive, non invasive and has no side effects.. Ample of studies exist that document music's powerful benefits including a significant reduction in the amount of anesthesia needed(1).

We all know Patients coming to Operation room (OR) are worried, need privacy, silence \& reassurance. Noises and comments in operation room range from sounds from scissors, drills, saws.etc to comments \& remarks on patient's disease, body shape, weight, behavior ...etc. These are key areas of ethics in operation theatre, which expects noise should be kept to minimum. Discussions \& stories should be in staff rooms only, away from patients! Jokes and laughing should not be done before induction of general anaesthesia or loudly in front of patients under local or regional anaesthesia,especially in languages that they understand. Deficiencies exist in the application of some ethical standards inspite of all measures.

Hence the purpose of our study was to find out whether patients undergoing elective surgery under regional anesthesia, who hear a pre-selected music during surgery through a head-phone, need a lower dose of intra-operative sedatives and have a reduced recall of intra-operative processes? 


\section{METHODS AND MATERIALS:}

Setting: The present study was carried out in the Department of Anaesthesiology at MGIMS-Sevagram which is a rural 648 bedded tertiary care hospital and Medical college located at Sevagram, District Wardha, State of Maharashtra, India.

Study design: This randomized, single blinded controlled trial was carried out after seeking approval from institutional ethical committee in adult patients fulfilling inclusion criteria's as mentioned below and who were scheduled for surgeries under regional anesthesia between May to July 2009 and who had given informed written consent for willingness to participate in this study .

The patient since aware of the type of intervention couldnot be blinded in our study.

Inclusion criteria were:

Patients for elective surgeries planned under Spinal anaesthesia,

ASA status I or II

Age group 18-60 years

Either liking music or ambivalent

Exclusion criteria were:

Age $<18,>60$ years

ASA status III and above

Pts with hearing impairment

Known psychiatric or memory disorder

Unwillingness to participate in the study(no Consent)

Disliking for Music

Special materials used were:

Portable music player

Head phone sized enough to cover whole ear

Choice of music selection

Screening: Starting from $1^{\text {st }}$ May 2009 till July 2009 , all patients who were posted in the OT list of gynaecology ,orthopedics or urology for surgery under regional anaesthesia were screened and included in this study. These specefic branches were preferred since the procedures in these branches often range between avg. to long duration and due to specific positions required to carry out surgeries in these patients, such patients often need supplemental sedation. Routinely in our setup we use Midazolum 1 to $2 \mathrm{mg}$ IV as initial bolus followed by further supplemental doses of approx. $1 \mathrm{mg}$ as and when the supervising anesthesiologist may feel necessary, so as to reduce their discomfort, pain or to make up for the weaning effect of anaesthesia. On an average 4-8 cases are scheduled for surgery under regional anaesthesia in the operative list of gynaecology ,orthopedics or urology combined at our centre. All these patients were evaluated atleast 1 day prior to their surgery in the pre-anaesthesia check-up O.P.D (PAC O.P.D) where we selected our study group based on inclusion and exclusion criteria above and desired their voluntary participation.

Study procedure:

Pre-op room: In this study we randomly divided all such patients fulfilling our inclusion criterias into 2 groups..Group M was the one in which Music of patient's choice from 3 categories "spiritual", "filmy", "instrumental" all of which were in patient's preferred language was provided. Group C received no music through music player but were still given headphones to wear. Selection to Music or No Music group was made from pre-sealed envelopes containing paper -chits with letter $\boldsymbol{M}$ (music) or letter $\boldsymbol{C}$ (Control i.e no music) which was picked up by patients themselves in presence and supervision by Person ' $A$ ' in pre op waiting area, who did not participate in further study procedure inside the operation room. Any spontaneous reporting of anxiety, voluntary demand for sedation, observer assessment of sedation/alertness score(OAS) ,Heart rate, NIBP(Non invasive blood pressure) were noted as baseline values. Group C received Midazolum $1 \mathrm{mg}$ IM atleast for 1 hour before finally transferring to Operation room(OR) whereas Music was applied in the Group M similarly for the same minimum duration of 1 hour.

Operation room: After an hour of application of the head phones with volume adjusted by patient themselves , pts were shifted to the OR (operation room) and Person 'B' who was blinded from details of the study and group differentiation supervised notification of all data intra-operatively. Inside the operation room, team of anaesthesiologists were totally blinded from the nature and purpose of the ongoing study with strict instruction not to touch the headphones or examine it for presence or absence of sounds. Routine monitors were attached to the patient, with recording of Pulse rate, NIBP,ECG,Pulse Oximetry,ETCO2 level (end tidal carbondioxide) at arrival and as were felt necessary for conductance of a particular case. All patients were placed an Inrtacath and site secured for IV access. Any self reported anxiety and/ or voluntary demand for sedation by patient at the beginning of the procedure was noted. All patients as usual received antiemetic and antacid prophylaxis by inj. Ondansetron $0.08 \mathrm{mg} / \mathrm{kg}$, and inj. Ranitidine $1 \mathrm{mg} / \mathrm{kg}$ respectively. Following this 
patients were given anaesthesia and initial 3 parameters Pulse rate, NIBP, plus level of sedation assessed on a simple 5 point sedation scale(OAS score) was noted, initially at $5 \mathrm{~min}$ interval for $30 \mathrm{~min}$ and subsequently at $10 \mathrm{~min}$ interval till completion of the surgery. Decision to give Inj. Midazolum was on assessment of sedation scale done by Person 'B' (blinded from the study protocol). Other parameters noted during course of the surgery were total duration of surgery, total dose of midazolum given intra -operatively, any complaints of pain, discomfort, signs of over sedation, fall In Spo2 $<95 \%$ and voluntary request for sedation.

Post-Op Wards: As a part of our secondary aim to assess patients recall of Operation room noises and their overall experience of the sedation method employed, Person C blinded from the group allocation and details of study protocol got answers filled to a questionnaire consisting of 5 questions (ment to judge patients recall of OR events) during the post operative visit on the same day evening as well got the VAS scale for intra- op pain, discomfort and dissatisfaction with the sedation method from the patient.

All patients as already mentioned received prior information regarding the study and any person who didnot consent to participate in the trial received usual care and attention as per departmental protocol. The sedative premedication on the operative day given before start of study in the pre op room was not calculated in dose requirements during the surgery. All above data were later assembled and then analyzed by investigators of this study.

Study variables : We collected the following variables in the study:

a) Demographic variables (Age,Sex,Education ,ASA-PS score \{American Society of Anaesthesiologist physical Status score \},Music listening habit), b)Surgical data ( duration, and type of surgery) b) any self reported anxiety before or during the surgery d) Number of voluntary requests for sedation before and during the surgery ,e) OAS score every 5 min (30 $\mathrm{min}$ ) and every $10 \mathrm{~min}$ thereafter f) total doses of Midazolum in mgs intra operatively f )VAS Scores for Intra- Op pain, discomfort and dissatisfaction g) Assesment of responses to 5 point Questionnaire.

Stastics: As our routine departmental practice is to give sedation in adult patients proposed for surgery under spinal/epidural anaesthesia with a starting dose of $1.5 \mathrm{mg}$ Midazolum and increments of $1 \mathrm{mg}$ as felt necessary by observer. The sedative dose requirement in each group more than $2 \mathrm{mgs}$ was measured and compared using a student's t-test. The Observer assessment of sedation/alertness scale(OAS score) $>3$ was taken as an positive event as OAS score of $<=3$ wastargeted to be achieved by either of the techniques as per our study protocol and VAS score for pain, discomfort or dissatisfaction more than $5 \mathrm{cms}$ (on a $1-10 \mathrm{cms}$ Scale) was accepted as a positive event. We defined a $\mathrm{p}$ value of $<0.01$ for each of these outcomes as indicative of a statistically significant difference in the intervention and standard care groups. The frequency of outcomes were indicated as control event rate (CER) for the no-music group and experimental event rate (EER) for the music group.The difference measure (absolute risk reduction or ARR) is also presented.

Sample size: This is first study of its kind in our hospital hence we have no clear idea regarding the exact sample size. One similar study in past judging effect of music on sedative requirements during spinal anaesthesia had total sample size of 50 i.e both intervention and control group. Here we included 60 patients as our sample size.

\section{OBSERVATION AND RESULTS:}

A total of 60 patients ,[Controll $\operatorname{Group}(C)=30$,Music Group $(M)=30]$ meeting our inclusion criteria were enrolled in this study. Mean age for both study groups combined was 39.9(12.8) years with minimum of 18 years and Maximum of 60 years. Male :female ratio was 31:29 (51.6\% vs 48.3\%). 38 (63.3\%) patients belonged to ASA I and $22(36.6 \%)$ to ASA II. All surgeries were Elective in nature with 33 out of 60 (55\%) were Orthopedic surgeries whereas 24(40\%) Gynaecological and $3(5 \%)$ Urological. Mean Duration of overall surgeries was between 121-180 min . Effectof Spinal blockade was complete as per desired level in all the 60 patients. There was no significant differences between the demographic and the surgical data amongst both the groups (See Table 1 ) viz., age, sex, education , nature of surgery,surgical department ,ASA physical status ,Music listening habit and the Mean duration of Surgery.Baseline record of variables like Self reported anxiety,Voluntary demand for Sedation, Heart rate Systolic and Diastolic BP were comparable in both the study groups and showed no significant difference ( $\mathrm{p}$ value of each variable > 0.01) (See Table1)When given the choice out of total 60 pts, maximum 16 $(53.3 \%)$ opted for instrumental music,whereas 11 (36.6\%) chosed Filmy songs and $3(10 \%)$ desired spiritual songs for listening during surgery.

Mean dose of Midazolum needed in the Controll group was $2.91+/-0.54 \mathrm{mgs}$ and was higher as compared to $1.13+/-0.36 \mathrm{mgs}$ required in the the Music listening group and this difference is found to be statistically significant (P value $<0.01$ ) (See Table 2 and Graph 1 ).Further "Absolute risk reduction"(ARR) for Midazolum dosage exceeding $2 \mathrm{mgs}$ significantly comes around $-90 \%$ falling within $95 \%$ confidence interval and stating that there is $90 \%$ chance of midazolum being needed more than $2 \mathrm{mgs}$ in the control group with no music. Observer's Assessment of sedation/Alertness score (OAS Score) tabulated every $30 \mathrm{~min}$ is as shown in (Table 2) and there was no statistical difference between the baseline OAS score of the two groups. Significant difference was observed between the two groups from baseline values to values at arrival. Control group patients were more awake than the Music group. OAS score at $30 \mathrm{~min}$ for control group showed 
lesser Mean OAS score (3.8+/-0.6) as compared to Music group(4.9+/-0.3). OAS score at 90 and 120 min in the Music group were $(3.0+/-0.5,2.7+/-0.5)$ respectively and were significantly lower $(\mathrm{P}$ value $<0.01)$ in comparison to the Study group $(3.5+/-0.6,3.5+/-0.8)$ respectively.OAS scores at $60,150,180,210 \mathrm{~min}$ intervals were comparable in both the groups with no statistical significance $(\mathrm{P}$ value $>0.01)$. Absolute risk reduction measuring events such as occurrence of OAS scores $>3$,i.e patients who could remain lightly sedated or fully alert despite receiving sedative medications were $23.3 \%$ in group of patients who received only Midazolum till arrival in OR.Chance of being awake or alert at 30 min from arrival in OR was $30 \%$ more in the music group at $90 \mathrm{~min}$ and $120 \mathrm{~min} 48.6 \%$ and $42.2 \%$ respectively higher in those receiving only Midazolum.VAS Score for pain during surgery in both the groups were 0 , VAS Score for discomfort during surgery in the control group was $0.66+/-1.59$ while that in the Music group was 0.16+-0.63, (Pvalue >0.01).VAS Score for Disatisfaction with the sedation method in the control group was 0.75(1.6) while that in the Music group was $0(0.0)$ and remained insignificant ( $\mathrm{P}$ value $>0.01$ ) (See Table 2). There was no significant Absolute risk reduction percentage for VAS scores of pain discomfort and dissatisfaction for either of the 2 sedation method.

The 5 questionnaire based assessment of the ability to recall intra operative events by patients in both the groups (See Table:2 and Graphs 3A and 3B) showed that initial 4 questions regarding instances of their transfer from pre operative waiting area to inside operation theatre, Insertion of spinal needle, IV access via Intracath, and Remembering start of their operation by surgical skin incision were remembered by both the groups equally without significant difference $(\mathrm{p}>0.01)$ and Absolute risk reduction was not significant.On asking to recall any conversation held by Doctors,Nurses, and /or other OR staff during his/her surgery it was observed that 15 patients of the control group remembered few statements/words(surely yes) amongst doctors as against only 2 patients of the Music group,however 15 patients of the control group heard something vague but couldn't recall exact words or sentences (indefinite) as against 10 from the Music group. While almost 18 patients from the Music group were almost completely unable to recall any of the talks amongst OR staff none of the midazolum group patient in our study showed such response.There was significant difference between the two study groups for reply to above question and absolute risk reduction was found to $60 \%$ meaning that Music group had $60 \%$ more chance of not recalling intra op conversations amongst staff compared to control group,(See Table 2, Graphs 3A and 3B ). On ability to recall any sounds of Machines, drills, saws, monitors, instruments etc during their surgery it was observed that 22 patients of the control group remembered few statements/words (surely yes) amongst doctors as against only 4 patients of the Music group, however 6 patients of the control group heard something vague but couldn't recall nature of sounds relating to drills,saws,monitors,instruments etc (indefinite) as against 4 from the Music group. While almost 22 patients from the Music group were totally unable to recall any of the instrument/equipment sounds inside the OR only 2 of the Controll group patient in our study showed total loss of recall.There was significant difference between the two study groups for reply to above question( $\mathrm{P}$ value $<0.01$ ). and music group had $66,6 \%$ more chance of not recalling instruments or monitors noise compared to the controll group(See: Table 2 and Graph 3A and 3B). 
IOSR Journal of Pharmacy

Vol. 2, Issue 3, May-June, 2012, PP.569-578

Table 1: Baseline Demographic and Surgical data

\begin{tabular}{|c|c|c|c|c|}
\hline VARIABLE & $\begin{array}{l}\text { GROUP } \\
\text { CONTROLL }(\mathrm{C}) \\
\mathbf{n = 3 0}\end{array}$ & $\begin{array}{l}\text { GROUP } \\
\text { MUSIC(M) } \\
\mathbf{n = 3 0}\end{array}$ & $P$ value & $\begin{array}{l}\text { Pvalue } \\
<0.01\end{array}$ \\
\hline Age (yrs) & $43.2(12.0)$ & $36.7(13.0)$ & 0.05 & NS \\
\hline $\begin{array}{l}\text { Gender: } \\
\text { Males } \\
\text { Females }\end{array}$ & $\begin{array}{l}12(40 \%) \\
18(60 \%)\end{array}$ & $\begin{array}{l}19(63.3 \%) \\
11(36.6 \%)\end{array}$ & 0.07 & NS \\
\hline $\begin{array}{l}\text { Education : } \\
<10 \text { th std } \\
10-12 \text { th std } \\
>12 \text { th std }\end{array}$ & $\begin{array}{l}13(43.3 \%) \\
11(36.6 \%) \\
6(20 \%)\end{array}$ & $\begin{array}{l}15(50 \%) \\
12(40 \%) \\
3(10 \%)\end{array}$ & 0.3 & NS \\
\hline Nature of surgery & Elective & Elective & - & NS \\
\hline $\begin{array}{l}\text { Department : } \\
\text { Orthopedics } \\
\text { Gynaecology } \\
\text { Urology }\end{array}$ & $\begin{array}{l}12(40 \%) \\
16(53.3 \%) \\
2(6.6 \%)\end{array}$ & $\begin{array}{ll}21 & (70 \%) \\
8 & (26.6 \%) \\
1 & (3.3 \%)\end{array}$ & 0.02 & NS \\
\hline $\begin{array}{l}\text { Total Mean Dur ation of } \\
\text { surgery } \\
\text { Code }(\mathrm{hrs})\end{array}$ & $1.9(0.08)$ & $1.5(0.07)$ & 0.02 & NS \\
\hline $\begin{array}{l}\text { ASA Status: } \\
\text { ASA status1 } \\
\text { ASA status2 }\end{array}$ & $\begin{array}{l}16(53.3 \%) \\
14(46.6 \%)\end{array}$ & $\begin{array}{ll}22 & (73.3 \%) \\
8 \quad(26.6 \%)\end{array}$ & 0.10 & NS \\
\hline $\begin{array}{l}\text { Pt likingMusic listening } \\
\text { Pt ambivalent for music } \\
\text { listening }\end{array}$ & $\begin{array}{l}13(43.3 \%) \\
17(56.6 \%)\end{array}$ & $\begin{array}{l}14(46.6 \%) \\
16(53.3 \%)\end{array}$ & 0.79 & NS \\
\hline $\begin{array}{l}\text { Pt who had Self reported } \\
\text { anxiety }\end{array}$ & $24(80 \%)$ & $21(70 \%)$ & 0.37 & NS \\
\hline $\begin{array}{l}\text { Pt who voluntary } \\
\text { demanded for sedation }\end{array}$ & $28(93.3 \%)$ & $27(90 \%)$ & 0.64 & NS \\
\hline Mean Heart Rate & $79.9(11.0)$ & $81.2(9.0)$ & 0.63 & NS \\
\hline Mean Systolic BP & $126(11.0)$ & $124.2(13.4)$ & 0.57 & NS \\
\hline Mean Diastolic BP & $78.5(7.6)$ & $78.8(6.3)$ & 0.87 & NS \\
\hline
\end{tabular}

Where $N S=$ Not significant 
IOSR Journal of Pharmacy

Vol. 2, Issue 3, May-June, 2012, PP.569-578

Table 2: Post Intervention Data

\begin{tabular}{|c|c|c|c|c|}
\hline VARIABLE & $\begin{array}{l}\text { GROUP } \\
\text { CONTROLL } \\
\text { (C) } \mathbf{n}=30\end{array}$ & $\begin{array}{l}\text { GROUP MUSIC } \\
\text { (M) } n=30\end{array}$ & $P$ value & $\mathbf{P}<\mathbf{0 . 0 1}$ \\
\hline $\begin{array}{ll}\begin{array}{l}\text { Intraoperative } \\
\text { doses(mgs) }\end{array} & \text { Midazolum } \\
\end{array}$ & $2.91(0.54)$ & $1.13(0.36)$ & 0.00 & $\begin{array}{ll}\begin{array}{l}P \\
<0.01\end{array} & \text { value } \\
\end{array}$ \\
\hline OAS base line & $5.0(0.0)$ & $5.0(0.0)$ & - & NS \\
\hline$O A S$ at atrrival in $O R$ & $5.0(0)$ & $4.4(0.1)$ & 0.002 & $\mathbf{P}<\mathbf{0 . 0 1}$ \\
\hline OAS at $30 \mathrm{~min}$ & $3.8(0.6)$ & $4.9(0.3)$ & 0.00 & $P<0.01$ \\
\hline$O A S$ at $60 \mathrm{~min}$ & $3.1(1.0)$ & $3.3(0.7)$ & 0.47 & NS \\
\hline OAS at 90 min & $3.5(0.6)$ & $3.0(0.5)$ & 0.002 & $\begin{array}{ll}\begin{array}{l}P \\
<0.01\end{array} & \text { value } \\
\end{array}$ \\
\hline OAS at $120 \mathrm{~min}$ & $3.5(0.8)$ & $2.7(0.5)$ & 0.001 & $\begin{array}{ll}\begin{array}{l}P \\
<0.01\end{array} & \text { value } \\
\end{array}$ \\
\hline$O A S$ at $150 \mathrm{~min}$ & $3.2(1.3)$ & $3.0(0.6)$ & 0.74 & NS \\
\hline OAS at 180 min & $3.5(0.7)$ & $3.5(0.7)$ & 1.0 & NS \\
\hline OAS at $210 \mathrm{~min}$ & -- & $4.0(0.0)$ & - & NS \\
\hline $\begin{array}{l}\text { PtS who had Self reported } \\
\text { anxiety }\end{array}$ & $2(6.6) \%)$ & $0(0 \%)$ & 0.1 & NS \\
\hline $\begin{array}{l}\text { PtS who voluntary demanded for } \\
\text { sedation }\end{array}$ & $5(16.6 \%)$ & $0(0) \%$ & 0.02 & NS \\
\hline $\begin{array}{l}\text { Mean VAS SCORE FOR PAIN } \\
\text { DURING SURGERY }\end{array}$ & 0 & 0 & - & NS \\
\hline $\begin{array}{lr}\text { Mean VAS } & \text { SCORE FOR } \\
\text { DISCOMFORT } & \text { DURING } \\
\text { SURGERY } & \\
\end{array}$ & $0.66(1.59)$ & $0.16(0.63)$ & 0.1 & NS \\
\hline $\begin{array}{lrr}\text { Mean VAS SCORE } & \text { FOR } \\
\text { DISATISFACTION } & \text { WITH } \\
\text { SEDATION METHOD } & \\
\end{array}$ & $0.75(1.6)$ & $0(0.0)$ & 0.014 & NS \\
\hline $\begin{array}{l}\text { 1-no. of Patients unable to recall } \\
\text { arrival in operation room from } \\
\text { pre op waiting area? }\end{array}$ & $0(0 \%)$ & $2(6.6 \%)$ & 1.0 & NS \\
\hline $\begin{array}{l}\text { 2- no.of Patients unable recall the } \\
\text { instance when IV ACCESS was } \\
\text { taken at their arm(INTRACATH)? }\end{array}$ & $0(0 \%)$ & $0(0 \%)$ & 1.0 & NS \\
\hline $\begin{array}{l}\text { 3-no.of Patients unable to recall } \\
\text { the instance when needle was } \\
\text { pricked at their back(SPINAL } \\
\text { NEEDLE)? }\end{array}$ & $0(0 \%)$ & $0(0 \%)$ & 1.0 & NS \\
\hline $\begin{array}{l}\text { 4-no. of Patients unable to recall } \\
\text { start of }\end{array}$ & $21(70.0 \%)$ & $23(76.6 \%)$ & 1.0 & NS \\
\hline $\begin{array}{l}\text { 5-no. of patients unable to recall } \\
\text { any conversation held by Doctors } \\
\text {, nurses, and /or other op room staff } \\
\text { during their surgery? }\end{array}$ & $0(0 \%)$ & $18(60 \%)$ & 0.0002 & $\begin{array}{ll}\begin{array}{l}\text { P } \\
<0.01\end{array} & \text { value } \\
\end{array}$ \\
\hline $\begin{array}{l}\text { 6-no of -patients unable to recall } \\
\text { sounds of Machines, drills } \\
\text {,saws,monitors, instruments etc } \\
\text { during their surgery? }\end{array}$ & $2(6.6 \%)$ & $22(73.3 \%)$ & 0.00 & $\begin{array}{l}\text { P value } \\
<0.01\end{array}$ \\
\hline
\end{tabular}


GRAPH: 1

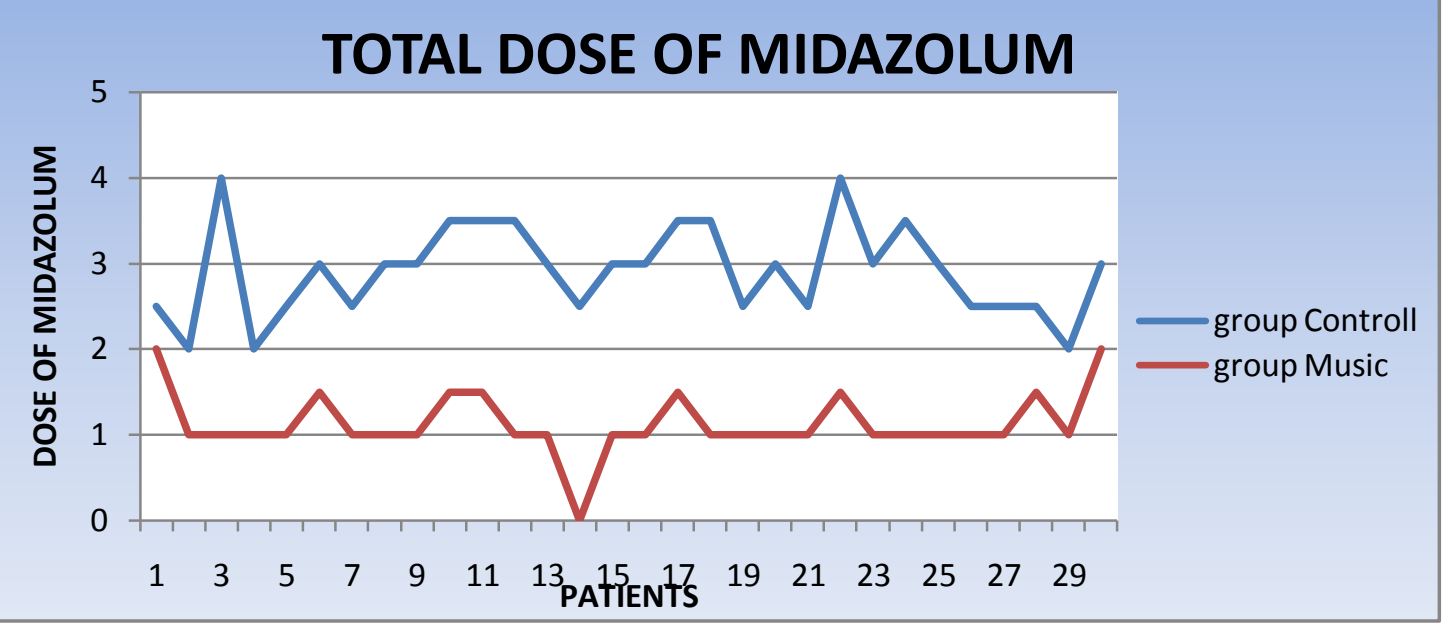

GRAPH 2:

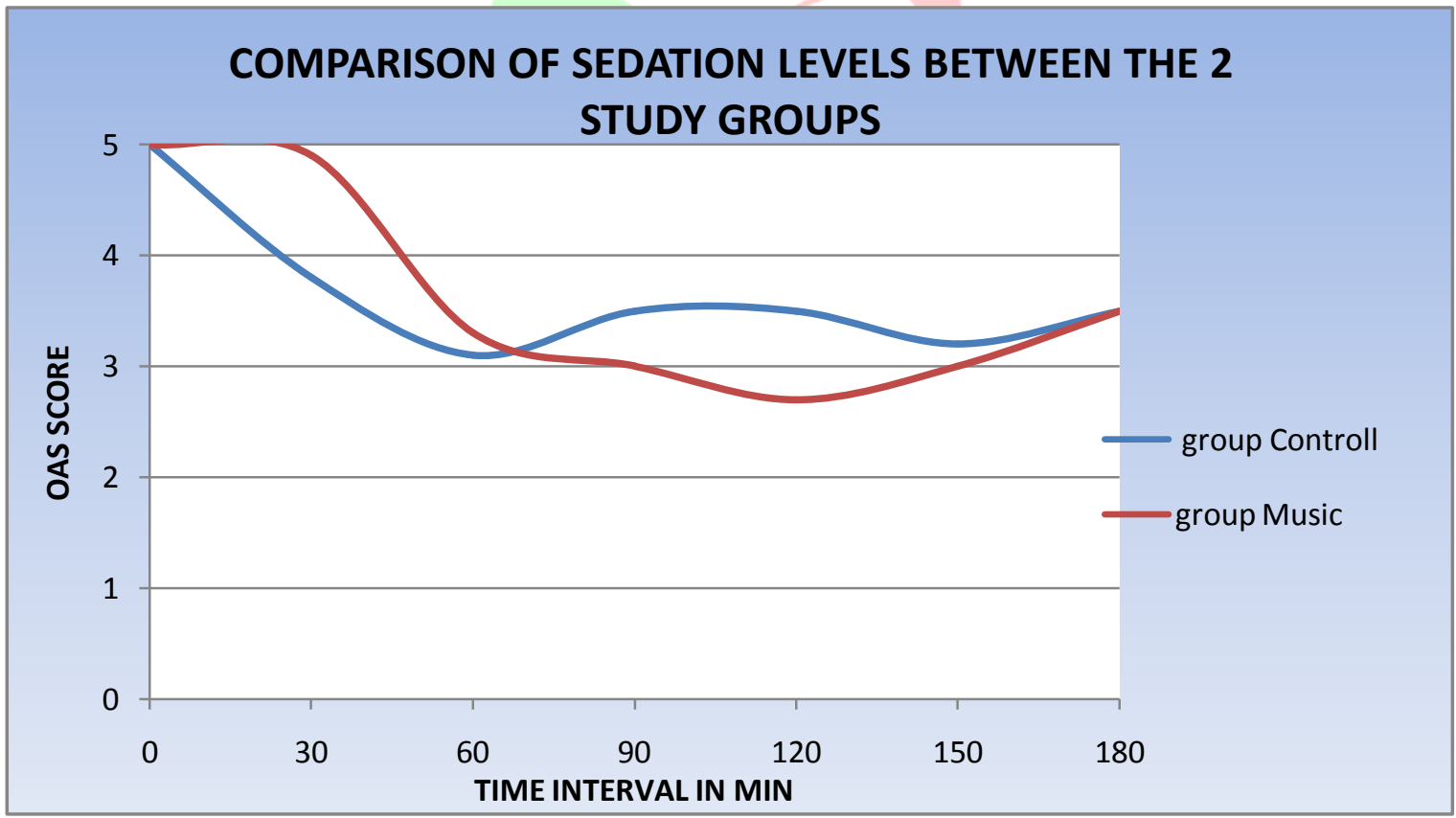


GRAPH: 3A AND 3B

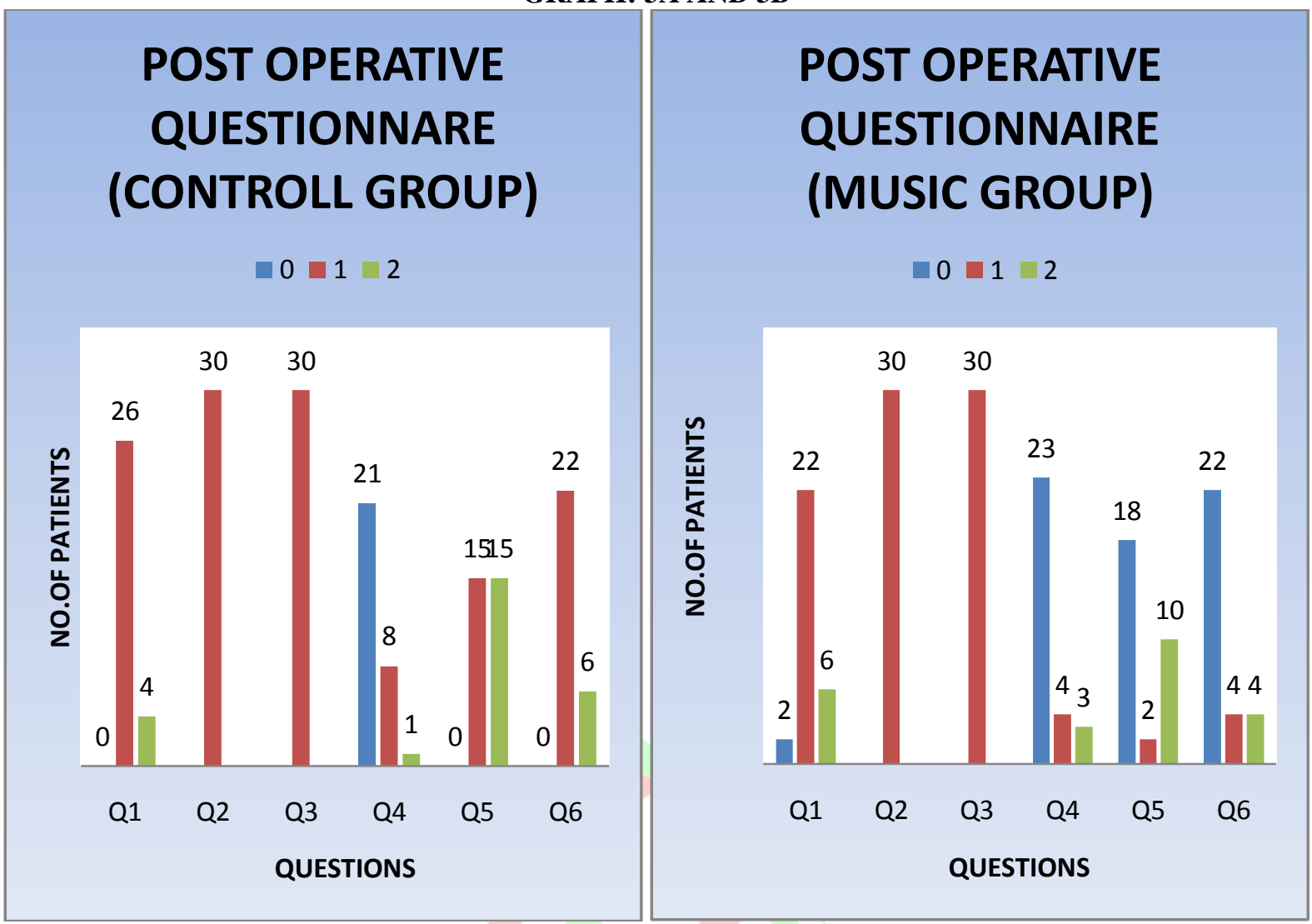

Please note: In graphs $3 \mathrm{~A}$ and $3 \mathrm{~B} \rightarrow 0=$ couldn't recall, $1=$ sure recall , $2=$ indefinite/unsure recall

\section{DISCUSSION:}

Use of music in operation theatre has been increasingly reported as well as recommended for beneficial effects on both patients as well as operation room staff. Since long promoters of Music therapy have been claiming effects of music on sleep and logical mechanisms behind it(10).

Our study had two basic parts one concerning the sedative aspect and the other on post operative recall of various intra operative events.The main findings of our study are that patients who listened to music during surgery required less doses of the sedative drug (midazolum) and that the desired level of Sedation was better achieved in the Music group as compared to the Non music group. Regarding Post operative Recall Of Intra operative events our study found out that patients who listened to Music via headphones could not recall conversations held by doctors, nurses, and /or other OR staff during their surgery and also the sounds of machines, drills, saws, monitors, instruments etc during their surgery were less heard and couldn't be subsequently recalled. Midazolum is one of the commonest drug used by anaesthesiologists for short term sedation ,anxiolysis and amnesia in variety of surgical patients. The drug's safety profile and short duration of action along with excellent amnesia reported with this drug makes it a popular choice among anaesthesiologists for regional anaesthesia and Day care surgical settings. Our routine departmental practice for regional anaesthesia cases also involves giving sedation to all adult patients with $1.5 \mathrm{mg}$ stat after spinal anaesthesia and $1 \mathrm{mg}$ top ups thereafter. Thus we counted all such patients who required top up of $1 \mathrm{mg}$ or more over the initial $1.5 \mathrm{mg}$ for maintaining sedation and hence a group of patients with a cutoff of mean dose requirement of more than $2 \mathrm{mg}$ was taken and analysed. Our study found significantly less requirement of midazolum needed for achieving desired level of sedation in the experimental group which is similar to findings of Caroline lepage et al (2) where they also reported decrease in midazolum doses in the music listening group to achieve a similar degree of relaxation. This could be due to the proposed theory of sedative action of music on mind and body so called mechanism known as "Brain entraintment"(15) . An article by B.M.Wiley states "Brain entraintment is essentially our brain's electrical response to an outside stimulus, usually light or sound. From whatever is captured by our eyes, the electrical responses that resonate within your brain are what you see. In other words, these result to an interpretation. This brain entrainment is called a Cortical Evoked Response. In terms of sound, brain entrainment takes place with a rhythmic beat. This rhythm is slowly reproduced by our brain until it resembles our brain waves. The interesting thing about our brains 
is that it has a tendency to fall into step with stimuli at the right frequencies. This is called Frequency Following Response. It's the 'Frequency Following Response' of our brains that brought about the development and science of binaural beats. Because the brain is such a receptive subject to outside stimulus, the changes in our brain wave frequencies that result go as far as changing our mental state of the moment. This is analogous to a person feeling very upbeat during exercise when he or she is listening to dance music. This is also the reason why meditation classes play soothing music in the background to help you relax and relieve stress. Sublimina "sleep tapes" and other types of CD tracks or machines that use binaural beats help people to fall asleep. Binaural beats work like this: Say that you have two different sounds. One sound is at $100 \mathrm{~Hz}$ while the other is at $104 \mathrm{~Hz}$. Because of the brain's natural tendency to synchronize what it's hearing with its own frequencies, it reproduces a $4 \mathrm{~Hz}$ beat - the difference between the two sounds. When our brain wave's frequency is anything below $5 \mathrm{~Hz}$, our state of consciousness is typically deep sleep. This beat therefore induces drowsiness and we get knocked out before we know it.With brain waves at 8 to $14 \mathrm{~Hz}$, we're in a relaxed state; at 14 to $30 \mathrm{~Hz}$, we're alert. Two sounds that are far too different then make no sense to the brain and therefore have no such altering effect to brain waves." (15) Effects of blocking of noise rather than direct action of Music as a suggested mechanism of better sedation ,have been suggested in few studies for eg :by Jin gu kang (16) where Patients were divided into three groups: noise, silence, and music . In the silence group, patients' ears were packed tightly to block ambient noise, whereas patient-selected music was applied to patients in the music group.BIS scores were similar in the noise and music groups. In our study we had blocked ambient noises in OR in the control group by applying well padded head phones in the control group as well which could dampen surrounding noise to eliminate this bias.Also the Music Offered to patients was of their choice of language and belonged to either of the three types viz instrumental,filmy or spiritual. Also quality of sound was ensured to be good to Avoid any possibility of Auditory fatigue as suggested by Caroline lepage in his study (2). Observer's Assessment of sedation/alertness score(OAS score) is believed to be best choice for precise assessment of sedation level (3) and hence was applied for judging sedation by us. To allow comparison between doses it was necessary that sedation level be same in both the groups and since our study was expecting to test post operative recall it was decided that at least OAS scores less than 3 be the target to be achieved in both the groups. Although constant plane below OAS $<=3$ was not achieved in few cases in our study so the data was interpreted with some limitations. The person giving sedative drug and noting the OAS score was blinded from the type intervention done in the patient by hiding music player inside non transparent linen to eliminate any Hawthrone Effect (Special Interest Taken by the investigator in the treatment arm)(13). We were slightly surprised to find out that OAS scores were significantly greater above 3 (100\%)in the Control group Compared to the Music group (76.6\%)on arrival in OR from the pre op waiting area .Almost 100\% awake state in the Controll group could have occurred due to our fixed $1 \mathrm{mg}$ dose selected for all patients irrespective of their weights and also partially because of the unexpected delay in shifting to OR on expected time . When OAS scores were compared at 30 min duration from the values noted at arrival in OR it was found out that the Music group had higher OAS $>3$ scores (100\%) this time as opposed to Controll group(70\%).This could be explained by the fact that midazolum which was given just after spinal anaesthesia, since rapidly acting would have caused quick fall in OAS scores leading to significant difference with Music group in which midaz was given only after 30 min period and when OAS scores were found to be more than 3. Further OAS scores at $60 \mathrm{~min}$ showed lower OAS values in both the groups but with no significant difference between the 2 groups. OAS scores at 90 and 120 min were higher in the control group(58.6 and 55.5\% resp) compared to music group(10\% and $6.6 \%$ resp ) and clearly suggested that Music group was better sedated in this duration range. The trend graph of OAS score shows that sedation within the music group although took longer to start around $60 \mathrm{~min}$ but was better maintained in plane compared to the other group at time between 90-120min. Since many surgeries ended in this time frame causing difference in number of observations in the two groups we did not compare OAS score beyond 120 min.VAS score on (0$10 \mathrm{cms}$ scale) for Pain,Discomfort and Amount of dissatisfaction with the sedative method used with positive event considered as scales marked above 5 were comparable in both groups. Analysis of the 5 point questionnaire on various events of recall showed that there was no significant difference between the 2 study groups for the first four questions. We feel that in the OR ,intra cath and spinal needle prick and surgical skin incision all happened at a duration quite early after patients arrival in the OR and poor amnesia for such events could have occurred because of the lack of appropriate sedation levels at these time periods which was influenced by a multiple factors such as patient handling, shifting to operating table, asking details of illness directly to patient by surgeons, pain of intracath and spinal needle and positioning for surgery etc. Significant difference was present in inability to recall the conversations cheld by Doctors ,nurses, and /or other OR staff during their surgery and the Music group faired better in this aspect .Similarly music group had less recall of intra operative sounds of monitors ,instruments etc,compared to the other group. Amnesia by midazolum is affected by the operating time (9). When a number of distinct Auditory signals are presented simultaneously ,it is often difficult for the human ear to distinguish or discriminate between each of them .This phenomenon known as 'Masking' ,accounts for the difficulty experienced in hearing others talk in the presence of loud background noise(5) .Hence even if the patients would have been in lighter planes of sedation in the music group, it is quite possible that due to 'Masking' patients of the music group did not recall verbal conversation and noises emerging from monitors or 
instrument's resectively by 60 and $66.6 \%$ more in comparison to the control group .But whether this inability to recall the operative events by Music listening is direct amnestic action of music or was merely due to 'Masking' effect described above could not be commented by our study design .

\section{CONCLUSION:}

Our study concludes that patients undergoing elective surgery under regional anesthesia, who hear a pre-selected music during surgery through a head-phone, need a lower dose of intra-operative sedatives and have a reduced recall of intraoperative processes thus creating an effective, safe and cheap non pharmacological method of sedating conscious patients operated under regional anaesthesia.We recommend that Favourite Music via headphones should be provided to all the patients who are fond of music listening during the Surgical procedures expected to last one and half hours or more .

\section{BIBLIOGRAPHY:}

[1] DR JAYRAMAN L, DR SHARMA S, DR SETHI N, DR SOOD J, DR KUMAR VP. Does intra operative music therapy or positive theurapeutic suggestions during general Anaesthesia affect the post operative outcome?-A double blinded randomised controlled trial. Indian J anaesth. 2006;50:258-61.

[2] LEPAGE C, DROLET P, GIRARD M, GRENIER Y, DEGAGNE R. Music decreases sedative requirements during spinal anesthesia. Anesth Analg. 2001;93:912-6.

[3] D. HO"HENER, S. BLUMENTHAL, A. BORGEAT. Sedation and regional anaesthesia in the adult patient. British Journal of Anaesthesia. 2008;100:8-16.

[4] AYOUB CM, RIZK LB, YAACOUB CI, GAAL D, KAIN ZN. Music and ambient operating room noise in patients undergoing spinal anesthesia. Anesth Analg. 2005;100:1316-9, table of contents.

[5] HODGE B, THOMPSON JF. Noise pollution in the operating theatre. Lancet. 1990;335:891-4.

[6] SHANKAR N, MALHOTRA KL, AHUJA S, TANDON OP. Noise pollution: a study of noise levels in the operation theatres of a general hospital during various surgical procedures. J Indian Med Assoc. 2001;99:244, 46-7.

[7] COL YUDHVIR SURI, LT COL NS LAMBA. Midazolum,a new more potent benzodiazepine ,compared with Diazepam as sedative during Spinal analgesia,A randomised double blind study. MJAFI. 2000;56:2932.

[8] COL YUDHVIR SURI. Evaluation of Midazolum and diazepam for pre operative Sedation. MJAFI. 2000;56:287-92.

[9] G W BELL, P J KELLY. A study of anxiety, and midazolam-induced amnesia in patients having lower third molar teeth extracted British journal of oral and maxillo facial surgery. 2000;38:596-602.

[10] DAVID ALDRIDGE. The Music of the Body:Music therapy in Medical Settings. advances. 1993;9.

[11] KOCH ME, KAIN ZN, AYOUB C, ROSENBAUM SH. The sedative and analgesic sparing effect of music. Anesthesiology. 1998;89:300-6.

[12] OVAYOLU N, UCAN O, PEHLIVAN S, et al. Listening to Turkish classical music decreases patients' anxiety, pain, dissatisfaction and the dose of sedative and analgesic drugs during colonoscopy: a prospective randomized controlled trial. World J Gastroenterol. 2006;12:7532-6.

[13] HARIKUMAR R, RAJ M, PAUL A, et al. Listening to music decreases need for sedative medication during colonoscopy: a randomized, controlled trial. Indian J Gastroenterol. 2006;25:3-5.

[14] TANG CS, KO CJ, NG SM, et al. ["Walkman music" during epidural anesthesia]. Gaoxiong Yi Xue Ke Xue Za Zhi. 1993;9:468-75.

[15] B M WILEY. Brain Entrainment: The Science Behind Meditation Music

[16] KANG JG, LEE JJ, KIM DA M, et al. Blocking noise but not music lowers bispectral index scores during sedation in noisy operating rooms. J Clin Anesth. 2008;20:12-6. 